\title{
Intensidade da ferrugem asiática (Phakopsora pachyrhizi H. Sydow \& P. Sydow) da soja [Glycine max (L.) Merr.] nas cultivares Conquista, Savana e Suprema sob diferentes temperaturas e períodos de molhamento foliar
}

\author{
Marcelo Carvalho Alves ${ }^{1}$; Edson Ampélio Pozza ${ }^{2}$; Josimar Batista Ferreira ${ }^{2}$; Dejânia Viera de de Araújo ${ }^{2}$; João de
} Cássia do Bomfim Costa ${ }^{3}$; Carolina Cardoso Deuner ${ }^{2}$; Maria de Fátima Silva Muniz ${ }^{4}$; Elizandra Batista Zambenedetti²; José da Cruz Machado ${ }^{2}$

\begin{abstract}
${ }^{1}$ Universidade Federal de Lavras, Departamento de Agricultura, CP 37, CEP 37200-000, Lavras, MG, Bolsista da Capes, e-mail: marcelocarvalhoalves@gmail.com; ㄹniversidade Federal de Lavras, Departamento de Fitopatologia, CP 37, CEP 37200-000, e-mail: eapozza@ufla.br. ${ }^{3}$; CEPEC/CEPLAC/MAPA, Seção de Fitopatologia, Cx.Postal 07, CEP. 45650-000, Itabuna, Bahia; ${ }^{4}$ Universidade Federal de Alagoas, CECA, Departamento de Fitotecnia e Fitossanidade, CEP 57100-000, Rio Largo, AL.

Autor para correspondência: Marcelo Carvalho Alves

Data de chegada: 10/06/2005. Aceito para publicação em: 26/10/2006.
\end{abstract}

\section{RESUMO}

Alves, M. C.; Pozza, E. A.; Ferreira, J. B.; Araújo, D. V.; Costa, J. C. B.; Deuner, C. C.; Muniz, M. F. S.; Zambenedetti, E. B.; Machado, J. C., Intensidade da ferrugem asiática (Phakopsora pachyrhizi H. Sydow \& P. Sydow) da soja [Glycine max (L.) Merr.] nas cultivares Conquista, savana e suprema sob diferentes temperaturas e períodos de molhamento foliar. Summa Phytopathologica, v.33, n.3, p.239-244, 2007.

RESUMO: A Ferrugem Asiática (Phakopsora pachyrhizi H. Sydow \& P. Sydow), relatada em diversas regiões do globo terrestre de climas tropicais e subtropicais, causa redução significativa na produtividade da soja [Glycine max (L.) Merr.]. Fatores bióticos como interação patógeno-hospedeiro e abióticos influenciam o progresso da doença. Objetivou-se neste trabalho estudar os efeitos da temperatura e de períodos de molhamento foliar no progresso da Ferrugem Asiática nas cultivares Conquista, Savana e Suprema. O experimento foi conduzido no Departamento de Fitopatologia da Universidade Federal de Lavras, em junho de 2004, em câmaras de crescimento vegetal nas temperaturas de $15,20,25$ e $30{ }^{\circ} \mathrm{C}$ e períodos de molhamento foliar de $0,6,12,18$ e 24 horas. A inoculação foi realizada pulverizando-se as plantas com suspensão de $10^{4}$ uredósporos de P. pachyrhizi.mL $\mathrm{mL}^{-1}$ de água. Dados da incidência e da severidade foram utilizados para avaliar o progresso da doença e integrados por meio da área abaixo da curva de progresso da incidência (AACPI) e da severidade (AACPS). Modelos de regressão não-linear foram ajustados para a AACPI e AACPS. Foi calculado o volume abaixo da superfície de resposta para incidência (VASRI) e severidade (VASRS) em relação à temperatura e molhamentos foliares com o objetivo de detectar diferenças entre cultivares. Molhamentos foliares acima de 15 horas e temperaturas próximas a $20^{\circ} \mathrm{C}$, nas 3 cultivares avaliadas, determinaram maior intensidade da Ferrugem Asiática. Temperaturas próximas a 30 e 15 ${ }^{\circ} \mathrm{C}$ ocasionaram menor intensidade da doença. Períodos de molhamento foliar abaixo de 6 horas reduziram a intensidade da doença. Todas as cultivares testadas foram suscetíveis à doença, entretanto, a cultivar Conquista apresentou maior VASRI e VASRS da Ferrugem Asiática comparada às cultivares Savana e Suprema, as quais não diferiram estatisticamente. Houve diferença entre as cultivares para AACPI em cada temperatura e molhamento foliar.

Palavras-chave adicionais: severidade, incidência, epidemiologia.

\section{ABSTRACT}

Alves, M. C.; Pozza, E. A.; Ferreira, J. B.; Araújo, D. V.; Costa, J. C. B.; Deuner, C. C.; Muniz, M. F. S.; Zambenedetti, E. B.; Machado, J. C.,. The Effects of temperature and leaf wetness periods on the development of soybean rust in the cultivars Consquista, Savana and Suprema. Summa Phytopathologica, v.33, n.3, p.239-244, 2007.

The asian rust (Phakopsora pachyrhizi Sydow) which has been reported in areas of tropical and subtropical climates around the world, causes significant soybean [Glycine $\max (\mathrm{L}$.) Merr.] yield reduction. The disease progress is influenced by biotic factors as interaction pathogen-host and abiotic factors of the environment. The objective of this work was to study the effects of temperature and leaf wetness period in the asian rust progress in the cultivars Conquista, Savana and Suprema. The experiment was conducted at the Department of Plant Pathology at Federal University of Lavras, in growth chamber at temperatures of $15,20,25$ and $30{ }^{\circ} \mathrm{C}$ and leaf wetness periods of $0,6,12,18$ and 24 hours. The plants were inoculated by spraying a suspension of inoculum of $P$. pachyrhizi at concentration of $10^{4}$ urediniospores. $\mathrm{mL}^{-1}$. Severity and incidence data were integrated by the area under disease progress curve for severity (AUDPCS) and incidence (AUDPCI). Non-linear regression models were adjusted for the disease severity (AUDPCS) and incidence (AUDPCI). Volume under the response surface of temperature and leaf wetness was calculated for incidence (VURSI) and severity (VURSS) to detect differences between cultivars. Higher soybean rust intensity occurred with leaf wetness above 15 hours and temperatures close to $20^{\circ} \mathrm{C}$, for the three tested cultivars. Temperatures above $30{ }^{\circ} \mathrm{C}$ and below $15{ }^{\circ} \mathrm{C}$ reduced the disease progress. Disease intensity was reduced in leaf wetness below 6 hours. All cultivars were susceptible, but higher VURSI and VURSS occurred in Conquista cultivar, followed by Savana and Suprema cultivars. Disease intensity was not statistically different between Savana and Suprema cultivars. Temperature and leaf wetness were different among cultivars for AUDPCI.

Additional Keywords: severity, incidence, epidemiology. 
A soja é cultivada em diversas regiões tropicais e subtropicais, das quais os Estados Unidos (EUA) e o Brasil são os maiores produtores e exportadores mundiais dessa cultura $(2,5,6)$. No Brasil, a soja é a principal cultura agrícola destinada à exportação. Segundo a Companhia Nacional de Abastecimento e o Departamento de Agricultura dos Estados Unidos da América, citados por Agrianual (2), na safra 2004/ 2005, os EUA produziram 78.289.000 megagramas relativas à área de 29.807 .000 hectares, com produtividade de $2.627 \mathrm{~kg} / \mathrm{ha}$, seguido pelo Brasil, com produção de 61.122 mil megagramas, relativas à área de 22.722.000 hectares e produtividade de $2.690 \mathrm{~kg} / \mathrm{ha}$ (2). Apesar da elevada produção, muitos fatores podem afetar a produtividade, tais como as doenças de plantas. Entre essas doenças, encontra-se a ferrugem asiática da soja (Phakopsora pachyrhizi H. Sydow \& P. Sydow) (6), relatada em diversas regiões do mundo como a responsável por reduções significativas de produtividade $(5,11,13,16,18,23,25,28,29,30)$.

A ferrugem ocorre em quase todas as áreas produtoras de soja do Brasil. Os estados mais atingidos na safra 2003/04 foram Mato Grosso, Goiás, Minas Gerais e São Paulo (30). Na safra 2002/03, no Brasil, a Ferrugem Asiática causou perdas estimadas em 4,011 milhões de megagramas ou o equivalente a US\$ 884,25 milhões, enquanto em 2004, considerando perda de grãos, custo de controle e queda de arrecadação, os prejuízos foram da ordem de US\$2,28 bilhões (30).

O sucesso da infecção do patógeno depende da seqüência de eventos determinada pela germinação de esporos, formação de apressório e penetração. Cada um desses eventos e a subseqüente colonização e esporulação são influenciadas por fatores bióticos como interação patógeno-hospedeiro (4) e fatores abióticos do ambiente (26). Entre os fatores abióticos, a temperatura e o molhamento foliar exercem papel fundamental, principalmente nos processos monocíclicos de germinação e de infecção de $P$. pachyrhizi em soja. Esses dois fatores abióticos foram estudados em cultivares adaptadas a outros países (5, $6,7,9,15,17,18,22,23,24)$. Em sua revisão, Sinclair \& Backman (23) citaram o intervalo de temperatura ótima para a infecção entre 20 a $25^{\circ} \mathrm{C}$. Nessas condições, e havendo disponibilidade de água livre sobre a superfície da planta, a infecção ocorre no período de 6 horas após a deposição do esporo, sendo que quanto maior a duração do molhamento foliar, maiores serão as chances de sucesso no estabelecimento da infecção (23). Já Vale et al. (26) estudando o efeito da temperatura e duração do molhamento foliar sobre a infecção de $P$. pachyrhiz na cultivar Paraná, observaram o número máximo de lesões. $\mathrm{cm}^{-2}$ de área foliar sob temperatura de $20^{\circ} \mathrm{C}$, com 24 horas de molhamento na superfície foliar. Assim, tais variáveis foram utilizadas para modelar, simular e prever a ferrugem asiática por alguns autores, utilizando cultivares adaptadas aos seus países $(3,19,20,27)$. Dessa forma, tais estudos são importantes para prever a ocorrência e formular estratégias de controle da doença, além de verificar o potencial de perdas causadas pela doença nas principais regiões produtoras durante a estação de crescimento $(5,19)$.

Diante disso, o objetivo do trabalho foi estudar o efeito do binômio temperatura e molhamento foliar na incidência e na severidade da ferrugem asiática da soja nas cultivares Conquista, Savana e Suprema.

\section{MATERIAL E MÉTODOS}

$\mathrm{O}$ experimento foi realizado em câmaras de crescimento e o delineamento utilizado foi em blocos ao acaso, em esquema fatorial 4 x 5 com 3 repetições, sendo 4 temperaturas $\left(15^{\circ} \mathrm{C}, 20^{\circ} \mathrm{C}, 25^{\circ} \mathrm{C}\right.$ e 30 $\left.{ }^{\circ} \mathrm{C}\right)$ e 5 períodos de molhamento foliar $(0,6,12,18$ e 24 horas $)$.

Sementes de soja, das cultivares suscetíveis (31), Conquista, Savana e Suprema foram plantadas em vaso contendo $5 \mathrm{~kg}$ da mistura solo, areia e matéria orgânica (esterco bovino) na proporção 2:1:0,5. Foi realizado desbaste 15 dias após o plantio deixando duas plantas por vaso, sendo essa a parcela experimental. As plantas foram mantidas em casa-de-vegetação até o estádio vegetativo $\mathrm{V}_{3}$, de acordo com a escala fenológica da soja proposta por Ritchie et al. (21). O inóculo do fungo foi obtido mediante a coleta de uredósporos de P. pachyrhizi diretamente de plantas doentes, cultivar Conquista, em casa-devegetação, e armazenado em nitrogênio líquido a $-180^{\circ} \mathrm{C}$ para preservar os uredospores por mais tempo e recuperar sua viabilidade (Zambenedetti, 2005). Foi realizado teste para verificar a viabilidade do inóculo antes da inoculação, o qual apresentou $89 \%$ de germinação.

A inoculação foi realizada pulverizando-se todas as folhas das plantas com suspensão de $10^{4}$ uredósporos de $P$. pachyrhizi.mL ${ }^{-1}$ até o ponto de escorrimento. Para obter os diferentes períodos de molhamento foliar as plantas recém pulverizadas foram mantidas em câmara úmida, com sacos de plástico transparentes, pelo período de cada tratamento. No tratamento de $0 \mathrm{~h}$ de molhamento, as plantas foram levadas sem câmara úmida para as câmaras de crescimento, permitindo a secagem rápida da suspensão pulverizada. As irrigações foram realizadas depositando água diretamente no colo das plantas. $\mathrm{O}$ experimento foi conduzido até o 15 으 dia após a inoculação.

Foram realizadas quatro avaliações de severidade e de incidência no folíolo central de todos os trifólios de cada planta. A incidência foi avaliada pela porcentagem de trifólios centrais com sinais da doença em relação ao total de trifólios da planta. A severidade foi obtida, nos mesmos trifólios, utilizando-se a escala de notas de Bromfield (6): nota $0=0 \%$, nota $1=0,15 \%$, nota $2=1,0 \%$, nota $3=2,5 \%$, nota $4=$ $8,0 \%$, nota $5=13,0 \%$.

Os dados de intensidade da doença foram integrados usando-se a área abaixo da curva de progresso da doença da incidência (AACPI) e da severidade (AACPS), de acordo com Campbell \& Madden (8) para cada combinação de temperatura e molhamento dentro de cada cultivar suscetível à doença (32). Utilizou-se a média da incidência e da severidade de todos os trifólios por avaliação para calcular a AACPI e AACPS.

$\mathrm{Na}$ análise de variância para AACPI e AACPS empregaram-se o esquema fatorial entre temperatura e molhamento foliar. As variáveis significativas no teste $\mathrm{F}$ foram submetidas à análise de regressão nãolinear de forma a obter uma equação para representar os efeitos da interação da temperatura com duração do molhamento foliar sobre a intensidade da ferrugem (20).

Para avaliar a diferença entre cultivares foi calculado o volume abaixo da superfície de resposta resultante da influência das temperaturas e dos períodos de molhamento foliar em cada cultivar, para incidência (VASRI) e para severidade (VASRS) da doença com o programa 'Volume Under Disease Response Surface' (14), considerando-se cultivares e repetições como fonte de variação. Da mesma forma, avaliou-se a diferença entre cultivares com relação às variáveis AACPI e AACPS. Nesse caso, foi utilizado o esquema fatorial triplo entre temperatura, molhamento foliar e cultivares. Em seguida, foi realizado o teste de médias de Tukey para VASRI, VASRS, AACPI e AACPS.

As análises estatísticas foram realizadas nos programas SISVAR v. 4,6 e STATISTICA v. 6.0 .

\section{RESULTADOS E DISCUSSÃO}

Os primeiros sinais da ferrugem apareceram na cultivar Conquista aos 6 dias após a inoculação e nas cultivares Savana e Suprema aos 9 dias após a inoculação, nos períodos de molhamento foliar de 6, 12, 18 
e $24 \mathrm{~h}$ e sob temperatura de 15,20 e $25^{\circ} \mathrm{C}$ para as cultivares Conquista e Savana e nas de 20 e $25^{\circ} \mathrm{C}$ para a cultivar Suprema (Figura 1). Já Bromfield et al. (7) estudando a o progresso da doença com diferentes isolados, observaram na cultivar Wayne, formação de urédias e lesões a partir de 6 a 7 dias após inoculação. Entretanto Vale et al. (26), avaliando a cultivar Paraná, observaram as primeiras urédias aos 9 dias sob temperatura de $20^{\circ} \mathrm{C}$ e aos 12 dias sob $24{ }^{\circ} \mathrm{C}$, ambos no período de molhamento de 12 a $24 \mathrm{~h}$. Assim, a diferença no período latente pode estar associada a características do hospedeiro, tanto na diferença entre genótipos quanto em seu estádio vegetativo e nutricional, bem como da combinação entre temperatura e molhamento foliar.

Verificou-se diferença significativa ( $\mathrm{P} \mathrm{d} \leq 0,01)$ para o VASRI e VASRS entre as cultivares Conquista, Savana e Suprema. A cultivar a

C
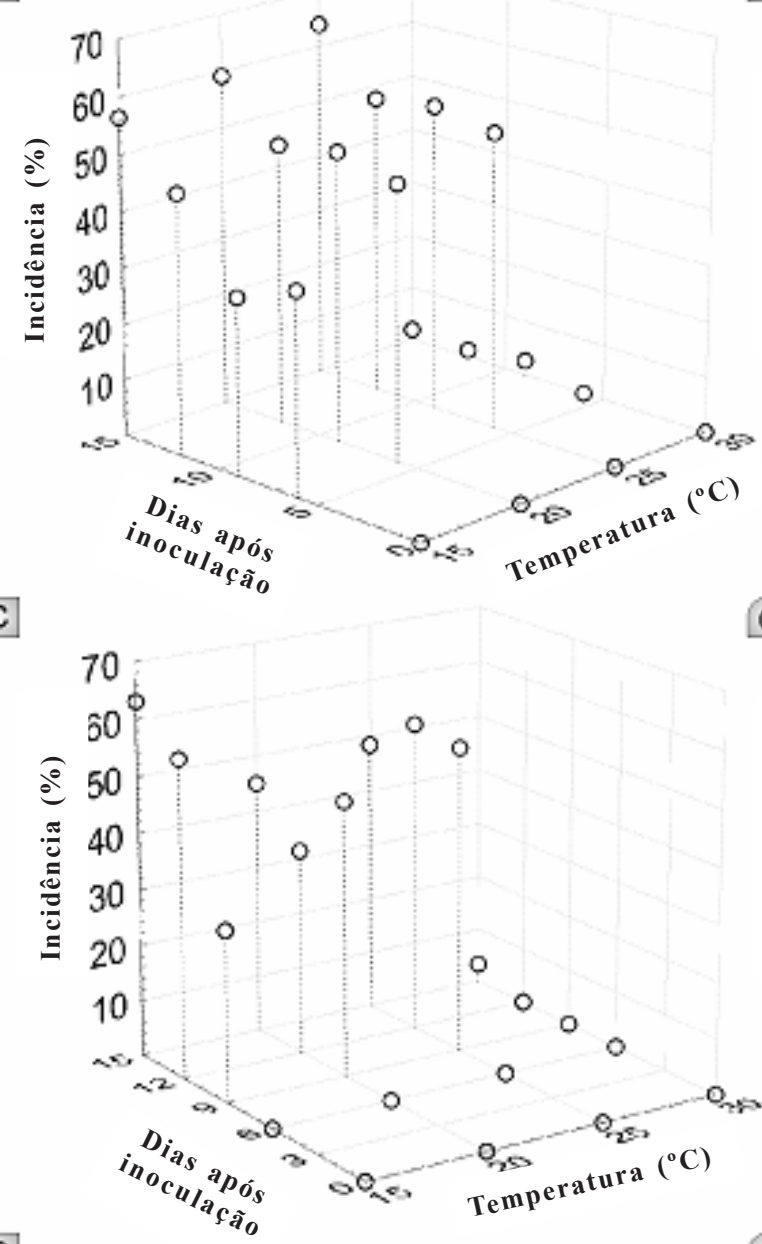

e

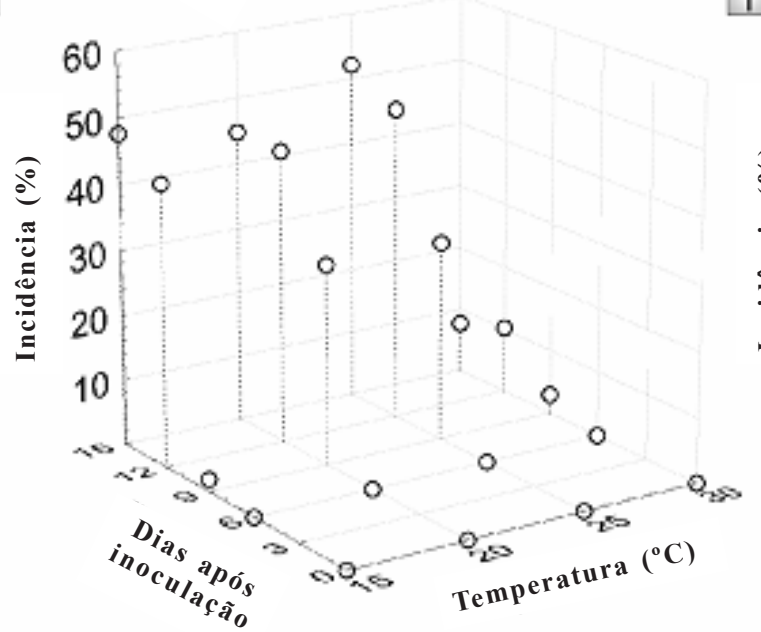

b

d
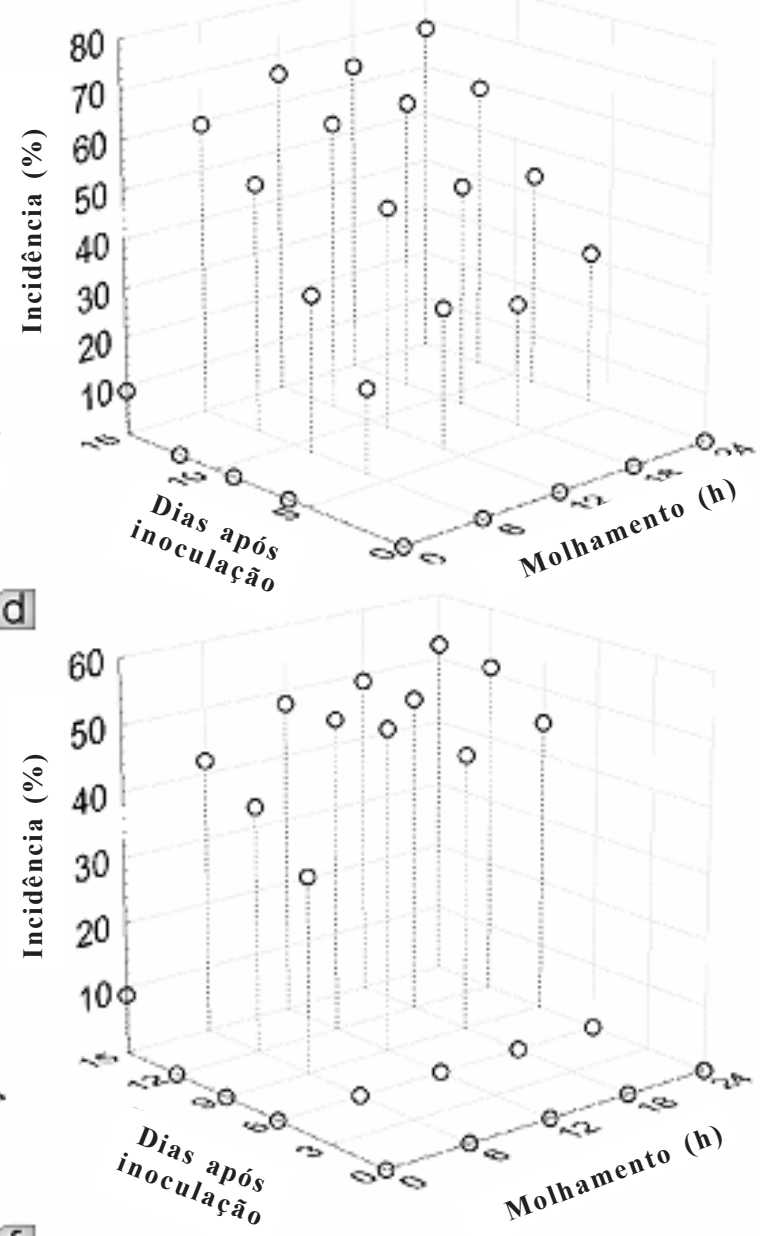

f

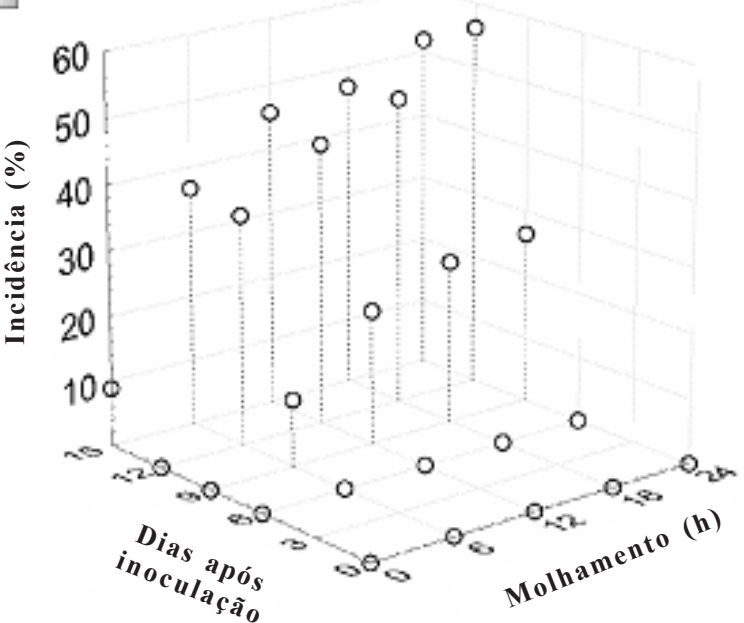

Figura 1. Representação tridimensional da incidência média de Phakopsora pachyrhizi ao longo do tempo, de acordo com a variação da temperatura (a, c, e) e do número de horas de molhamento foliar (b, d, f), nas cultivares de soja (Glycine max L.) Conquista (a, b), Savana (c, d) e Suprema (e, f) 
Conquista apresentou maiores VASRI e VASRS. As cultivares Savana e Suprema não diferiram entre si (Tabela 1). Zambenedetti (32) também observou diferenças entre cultivares de soja quanto a intensidade da ferrugem. Nesse caso, a partir da inoculação com suspensão de esporos de P. pachyrhizi em sete cultivares (Uirapuru, BRS 134, Pintado, BRS 154, BRS 215, FT2, BRS 231) e um genótipo PI459025, em casa-devegetação, observou-se maior AACPI nas cultivares BRS 134, FT2 e BRS 231, do que nas demais cultivares avaliadas. Além disso, essa mesma autora, ao estudar o processo de infecção a partir de material clareado e observado em microscópio de luz, não se observou diferença entre as cultivares com relação ao tamanho do tubo germinativo, mas houve diferença na porcentagem de germinação, na formação de apressório e na penetração.

Tabela 1. Comparação entre médias de volume abaixo da superfície de resposta da severidade (VACPS) e incidência (VACPI) da ferrugem da soja (Phakopsora pachyrhizi) em Glycine max cv. Conquista, Savana e Suprema sob diferentes temperaturas e períodos de molhamento foliar.

\begin{tabular}{ccc}
\hline Cultivares* & VACPI & VACPS \\
\hline Conquista & $283268,77 \mathrm{a}$ & $78820,56 \mathrm{a}$ \\
Savana & $210726,90 \mathrm{~b}$ & $42477,21 \mathrm{~b}$ \\
Suprema & $175301,32 \mathrm{~b}$ & $53726,60 \mathrm{~b}$ \\
Coeficiente de variação $(\mathrm{CV} \%)$ & 4,14 & 6,03 \\
\hline
\end{tabular}

*Médias com mesma letra na coluna são estaticamente iguais pelo teste de Tukey $(\mathrm{Pd} \leq 0,05)$.

Tabela 2. Área abaixo da curva de progresso da incidência (AACPI) da ferrugem da soja (Phakopsora pachyrhizi) em Glycine max nas cultivares Conquista, Savana e Suprema sob diferentes temperaturas.

\begin{tabular}{|c|c|c|c|c|}
\hline Cultivar/Temperatura* & 15 & 20 & 25 & 30 \\
\hline Conquista & $255,34 \mathrm{a}$ & $321,87 \mathrm{a}$ & $339,61 \mathrm{a}$ & $5,77 \mathrm{a}$ \\
\hline Savana & $236,51 \mathrm{~b}$ & $215,22 \mathrm{~b}$ & $267,43 \mathrm{~b}$ & $3,20 \mathrm{a}$ \\
\hline Suprema & $137,62 \mathrm{~b}$ & $195,44 \mathrm{~b}$ & $208,81 \mathrm{c}$ & $34,03 \mathrm{a}$ \\
\hline $\mathrm{CV}(\%)$ & & & & \\
\hline
\end{tabular}

*Médias com mesma letra na coluna são estaticamente iguais pelo teste de Tukey $(\mathrm{Pd} \leq 0,05)$.

Tabela 3. Área abaixo da curva de progresso da incidência (AACPI) da ferrugem da soja (Phakopsora pachyrhizi) em Glycine max nas cultivares Conquista, Savana e Suprema sob diferentes períodos de molhamento foliar.

\begin{tabular}{|c|c|c|c|c|}
\hline Cultivar/Molhamento* & 6 & 12 & 18 & 24 \\
\hline Conquista & $241,25 \mathrm{a}$ & $302,27 \mathrm{a}$ & 297,60 a & $303,30 \mathrm{a}$ \\
\hline Savana & $176,89 \mathrm{~b}$ & $242,53 \mathrm{~b}$ & $231,11 \mathrm{~b}$ & $243,59 \mathrm{~b}$ \\
\hline Suprema & $127,76 \mathrm{c}$ & $173,65 \mathrm{c}$ & $192,44 \mathrm{c}$ & $217,21 \mathrm{~b}$ \\
\hline CV (\%) & \multicolumn{4}{|c|}{19,68} \\
\hline
\end{tabular}

* Médias com mesma letra na coluna são estaticamente iguais pelo teste de Tukey $(\operatorname{Pd} \leq 0,01)$.

A diferença entre cultivares também foi detectada com a interação significativa $(\mathrm{P} \mathrm{d}<0,01)$, tanto para AACPI entre temperaturas e cultivares quanto para molhamento foliar e cultivares (Tabelas $2 \mathrm{e}$ 3). Considerando-se o efeito entre temperatura e cultivares, observou-se não haver diferença entre as cultivares a $30^{\circ} \mathrm{C}$, porém nas demais temperaturas ocorreram diferenças, destacando-se a cultivar Conquista com maior AACPI. Com relação às cultivares Savana e Suprema, houve diferença somente na temperatura de 25 ${ }^{\circ} \mathrm{C}$, com maior AACPI para a cultivar Savana (Tabela 2). Para o número de horas de molhamento foliar também foi detectada diferença significativa, com exceção do período de 0 horas de molhamento para AACPI. A cultivar Conquista apresentou maior AACPI a 6, 12, 18 e 24 horas. A cultivar Savana apresentou maior AACPI que a cultivar Suprema, não diferindo apenas no período 24 horas de molhamento (Tabela 3 ).

Houve interação significativa da temperatura e molhamento foliar para AACPI dentro de cada cultivar avaliada $(\mathrm{p}<0,01)$, bem como para AACPS, nas cultivares Conquista $(p<0,05)$, Savana e Suprema $(\mathrm{p}<0,01)$. Com ajuste dos modelos de regressão não-linear para os dados de AACPI e AACPS, observou-se maior intensidade da doença nas cultivares Conquista, Savana e Suprema, sob períodos de molhamento foliar acima de 12 horas e temperaturas próximas a $20{ }^{\circ} \mathrm{C}$. Temperaturas acima de 28 e abaixo de $15{ }^{\circ} \mathrm{C}$, bem como períodos de molhamento foliar abaixo de 6 horas resultaram em menor AACPI e AACPS. No entanto, sob períodos de molhamento foliar próximos a $24 \mathrm{~h}$ e temperaturas próximas a 30 e $15{ }^{\circ} \mathrm{C}$ observou-se ocorrência da doença, porém em baixa intensidade (Figura 2),

De acordo com Alves (1), a temperatura ótima para infecção por $P$. pachyrhizi na cultivar Suprema é de $21,7^{\circ} \mathrm{C}$ sob período de molhamento foliar de 24 horas, porém Vale (24), estudando a cultivar Paraná, citou a temperatura de $20{ }^{\circ} \mathrm{C}$ em umidade relativa superior a $90 \%$, enquanto Casey (9), na Austrália, estudando o progresso da doença a partir de foco inoculado artificialmente na cultivar Lee, no campo, observou temperaturas de 18 a $26{ }^{\circ} \mathrm{C}$ e períodos de molhamento foliar de aproximadamente 10 horas por dia, como necessários para ocorrer epidemias com altas taxas de progresso da severidade. Na revisão de Sinclair \& Backman (23), citou-se como faixa de temperatura ótima para a infecção de $P$. pachyrhizi em soja de $20{ }^{\circ} \mathrm{C}$ a $25^{\circ} \mathrm{C}$, ou seja, todos esses autores citam temperaturas próximas a $20^{\circ} \mathrm{C}$, embora em alguns casos próxima a $25^{\circ} \mathrm{C}$, como a ideal para ocorrer a maior intensidade da doença, sempre com maiores períodos de molhamento foliar. Essas diferenças podem estar relacionadas a variações no genótipo do hospedeiro.

Em relação às temperaturas limitantes, Casey (9) citou valores acima de 30 e abaixo de $15{ }^{\circ} \mathrm{C}$ sob condições secas, ou seja, com poucas horas de molhamento, responsáveis por retardar o progresso da ferrugem. Já Marchetti et al. (15) estudando o efeito da ferrugem na cultivar Wayne, observou que plantas incubadas a $27,5^{\circ} \mathrm{C}$ não apresentaram infecção independentemente do período de molhamento (15). Da mesma forma, Melching et al. (18), estudando efeitos de temperatura e de períodos de molhamento foliar na ferrugem asiática da soja, em Taiwan, cultivar Wayne, não encontraram lesões a $9{ }^{\circ} \mathrm{C}$ e $28,5^{\circ} \mathrm{C}$ mesmo em períodos de molhamento de 20 horas. Assim, não observou-se infecção da doença nesses intervalos, nos trabalhos de Marquetti et al. (15) e de Melching et al. (18), diferindo do presente estudo, provavelmente devido a diferença de cultivares e do isolado da ferrugem utilizado

No modelo climático para previsão da ferrugem asiática da soja, no Brasil, Reis et al. (20), com base nos dados de Melching et al. (18) com a cultivar Wayne, propuseram valores diários de probabilidade de infecção de uredósporos com ocorrência de infecção mesmo em temperaturas próximas a $29^{\circ} \mathrm{C}$, com 16 horas de molhamento foliar e sob temperaturas mais baixas, de $9{ }^{\circ} \mathrm{C}$, com 11 horas de molhamento foliar, semelhante às situações verificadas no presente trabalho para as cultivares Conquista, Savana e Suprema e o isolado obtido em Lavras. Dessa forma, de acordo com o exposto anteriormente, dependendo da temperatura e do número de horas de molhamento foliar e da sua combinação, pode haver diferença na intensidade da doença, dependendo da cultivar. 
a

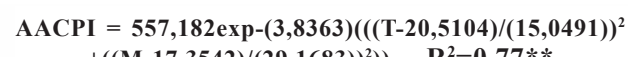
$\left.\left.+((\mathbf{M}-17,3542) /(29,1683))^{2}\right)\right) \quad \mathbf{R}^{2}=0,77 * *$

b

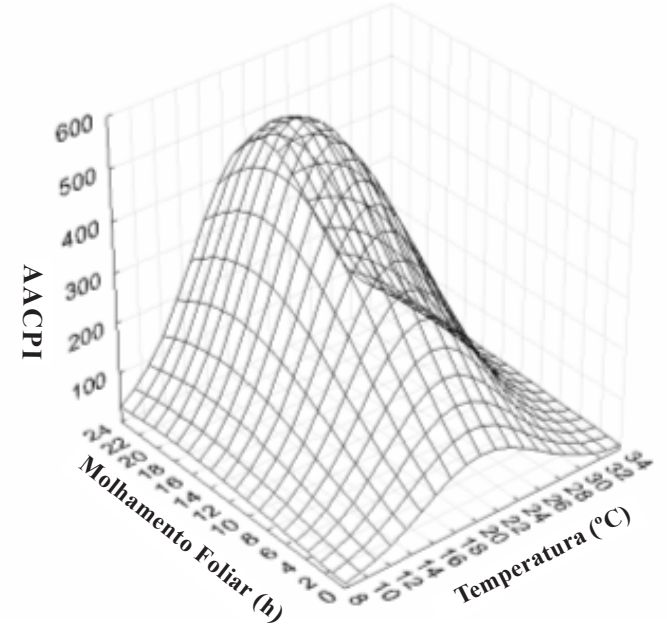

C

$$
\begin{gathered}
\text { AACPI }=408,431 \exp (-6,71891)\left(((T-19,4741) /(23,2664))^{2}\right. \\
\left.+\left(((M-17,8745) /(37,4345))^{2}\right)\right) \quad R^{2}=0,67 * *
\end{gathered}
$$

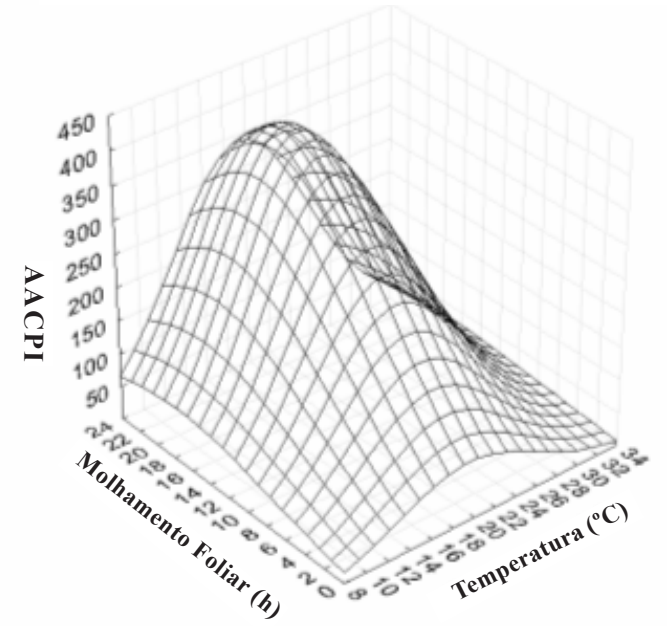

e

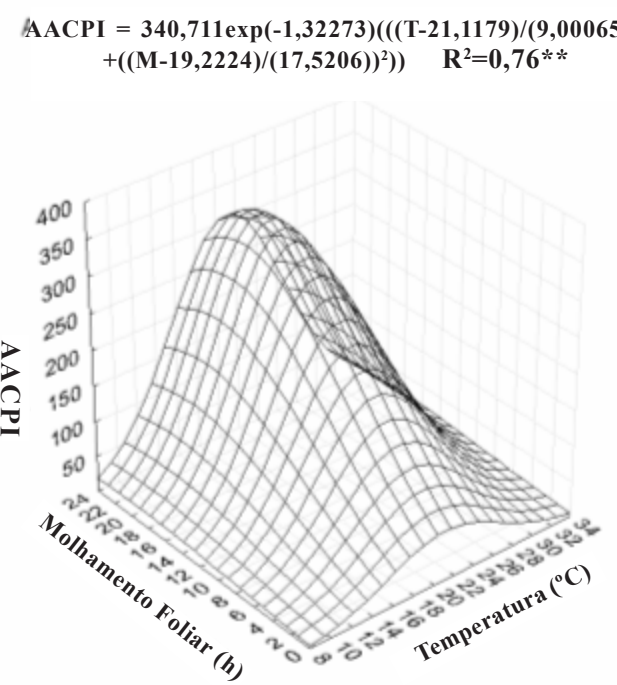

\section{AACPS $=1,6546 \exp (-6,84246)\left(((\mathrm{T}-19,4871) /(24,6295))^{2}\right.$} $\left.\left.+((\mathbf{M}-20,9021) /(42,1387))^{2}\right)\right) \quad \mathbf{R}^{2}=\mathbf{0 , 5 0 * *}$

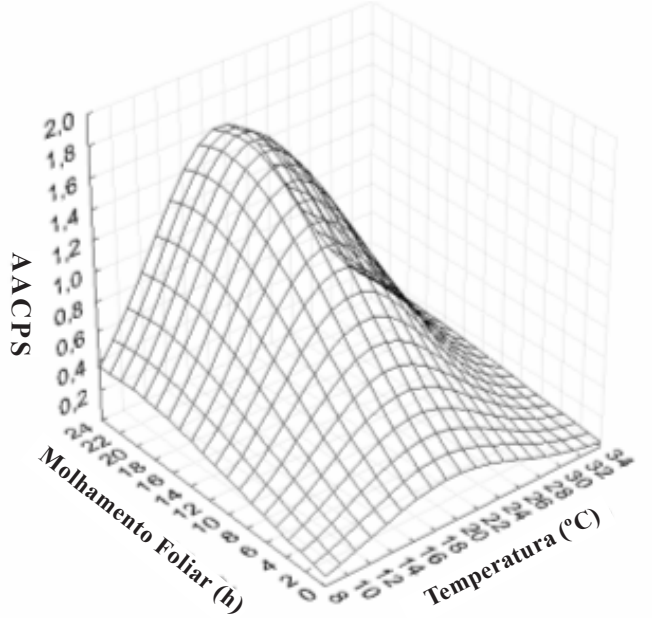

\section{AACPS $=0,967155 \exp -(19,2256)\left(((\mathrm{T}-20,9475) /(34,5077))^{2}\right.$ $\left.\left.+((\mathbf{M}-22,4356) /(\mathbf{7 5}, \mathbf{4 5 8 4}))^{2}\right)\right) \quad \mathbf{R}^{2}=0,57 * *$}

\section{AACPS $=1,99399 \exp (-61,473)\left(((T-22,1362) /(48,3311))^{2}\right.$ $\left.\left.+((\mathbf{M}-29,0547) /(147,917))^{2}\right)\right) \quad R^{2}=0,58 * *$}

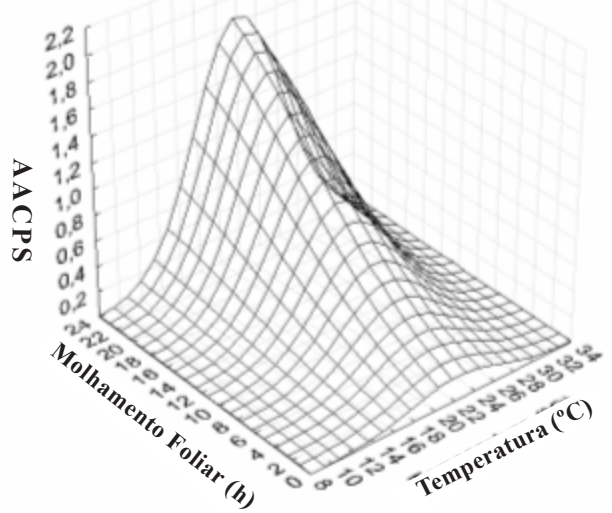

Figura 2. Representação tridimensional da incidência (a, c, e) e severidade (b, d, f) de Phakopsora pachyrhizi como uma função da temperatura (T) e do número de horas de molhamento foliar (M), nas cultivares de soja (Glycine max L.) Conquista (a, b), Savana (c, d) e Suprema (e, f). 


\section{REFERÊNCIAS BIBLIOGRÁFICAS}

1. Alves, M.C.; Pozza, E.A.; Costa, J.C.B. Incidência da ferrugem (Phakopsora pachyrhizi) da soja, cultivar suprema, em diferentes condições de temperatura e molhamento foliar. In: Simpósio sobre a Cultura da Soja, 1., 2004, Lavras, Anais. Univ. Federal Lavras, 2004. CD-ROM.

2. AGRIANUAL 2005: Anuário da Agricultura Brasileira. São Paulo: FNP, 2004. 521 p.

3. Batchelor, W.D.; Yang, X.B.; Tschanz, A. T. Development of a neural network for soybean rust epidemics. Transactions of the ASAE, St. Joseph, v.40, n.1, p.247-252, 1997.

4. Bromfield, K.R. Differential reaction of some soybean accessions to Phakopsora pachyrhizi. Soybean Rust Newsletter, Shanhua, v.4, n.2, 1981. (Abstract).

5. Bromfield, K.R. Soybean rust. St. Paul: American Phytopathological Society, 1984. 64p. (Monograph, 11).

6. Bromfield, K.R. World soybean rust situation. In: Hill, L. D. World Soybean Research: proceedings of the world soybean research conference. Danville: The Interstate Printers and Publichers, 1976. p.491-500.

7. Bromfield, K.R.; Melching, J.S.; Kingsolver, C.H. Virulence and Aggressiveness of Phakopsora pachyrhizi isolates causing soybean rust. Phytopathology, St. Paul, v.70, n.1, p.17-21, 1980.

8. Campbell, C.L.; Madden, L.V. Introducion to plant disease epidemiology. New York: Jonhn Wiley \& Sons, 1990. 532p.

9. Casey, P.S. The epidemiology of soybean rust - Phakopsora pachyrhizi Syd. Soybean Rust Newsletter, Shanhua, v. 4, n. 1, p.3-5, 1980 .

10. Dowler, W.M.; Rytter, J.L. Variability of host-reaction observed in response to Phakopsora-pachyrhizi sydow, causal agent of soybean rust. Phytopathology, St. Paul, v.74, n.6, p.756-756, 1984.

11. Hartman, G. L.; Miles, M. R.; Frederick, R. D. Breeding for resistance to soybean rust. Plant Disease, v. 89, n. 6, p. 664-666, 2005 .

12. Hartwig, E.E. Identification of a fourth major genes conferring to rust in soybeans. Crop Science, Madison, v.26, n.6, p.1135$1136,1986$.

13. Kawuki, R.S.; Tukamuhabwa, P.; Adipala, E. Soybean rust severity, rate of rust development, and tolerance as influenced by maturity period and season. Crop Protection, Oxford, v.3, n, 5, p.447-455, 2004

14. Maffia, L.A.; Berger, R.D. Models of plant disease epidemics. II: Gradients of bean rust. Journal of Phytopathology, Berlin, v.147, n.4, p.199-206, 1999.

15. Marchetti, M.A.; Melching, J. S.; Bromfield, K. R. The effects of temperature and dew period on germination and infection by uredospores of Phakopsora pachyrhizi. Phytopathology, St. Paul, v.66, p.461-463, 1976.

16. McGee, D.C. Soybean diseases: a reference source for seed technologists. St. Paul: The American Phytopathological Society, 1992. $151 \mathrm{p}$.

17. Melching, J.S.; Bromfield, K.R. Factors influencing spore germintation and infection by Phakopsora pachyrhizi and intensification and spread of soybean rust under controlled conditions.
Proceedings of the American Phytopathological Society, St. Paul, v.2, p.125, 1975. (Abstract).

18. Melching, J.S.; Dowler, W.M.; Koogle, D.L.; Royer, M.H. Effects of duration, frequency, and temperature of leaf wetness periods on soybean rust. Plant Disease, St. Paul, v.73, n.2, p. 117-122, 1989.

19. Pivonia, S.; Yang, X.B. Assessment of the potential year-round establishment of soybean rust throughout the world. Plant Disease, St. Paul, v.88, n.5, p.523-529, 2004.

20. Reis, E. M.; Sartori, A.F.; Câmara, R. K. Modelo climático para previsão da ferrugem da soja. Summa Phytopathologica, Botucatu, v.30, n.2, p.290-292, 2004.

21. Ritchie, S.; Hanway, J.J.; Thompson, H.E. How a soybean plant develops. Ames: Iowa State University of Science and Technology, Cooperative Extension Service, 1982. 20p. (Special Report, $53)$.

22. Sinclair, J. B. (Ed.). Compedium of soybean diseases. Minesota: American Phytopathological Society, 1975. 69p.

23. Sinclair, J.B.; Backman, P.A. (Ed.). Compendium of soybean diseases. 3.ed. St. Paul: APS Press, 1989. p. 24-27.

24. Vale, F.X.R. Aspectos epidemiológicos da ferrugem (Phakopsora pachyrhizi Sydow) da soja (Glycine max L. Merrill). 1985. 104p. Tese (Doutorado em Fitopatologia) - Universidade Federal de Viçosa, Viçosa, MG.

25. Vale, F.X.R.; Chaves, G.M.; Zambolim, L. Effect of planting time on the incidence of soybean rust. Soybean Rust Newsletter, Shanhua, v.7, p.4-6, 1985.

26. Vale, F.X.R.; Zambolim, L.; Chaves, G.M. Efeito do binômio temperatura-duração do molhamento foliar sobre a infecção por Phakopsora pachyrhizi em soja. Fitopatologia Brasileira, v.15, n.3, p.200-202, 1990

27. Yamaoka, Y.; Fujiwara, Y.; Kakishima, M.; Katsuya, K.; Yamada, K.; Hagiwara, H. Pathogenic races of Phakopsora pachyrhizi on soybean and wild host plants collected in Japan. Journal of General Plant Pathology, Tokyo, v. 68, n. 1, p.52-56, 2002.

28. Yang, X.B.; Dowler, W.M.; Tschanz, A.T. A simulation-model for assessing soybean rust epidemics. Journal of Phytopathology, Berlin, v.133, n.3, p.187-200, 1991.

29. Yang, X.B.; Tschanz, A.T.; Dowler, W.M.; Wang, T.C. Development of yield loss models in relation to reductions of components of soybean infected with Phakopsora pachyrhizi. Phytopathology, St. Paul, v.81, n.11, p.1420-1426, 1991.

30. Yang, X.B.; Royer, M.H.; Tschanz, A.T.; Tsai, B.Y. Analysis and quantification of soybean rust epidemics from 73 sequential planting experiments. Phytopathology, St. Paul, v.80, n.12, p.14211427, 1990.

31. Yorinori, J.T.; Lazzarotto, J.J. Situação da ferrugem asiática da soja no Brasil e na América do Sul. Londrina: Embrapa Soja, 2004. 30 p. (Documentos, 236). Disponível em $<$ http:// www.cnpso.embrapa.br $>$ em: $<$ dez. 2004.

32. Zambenedetti, E. B. Preservação de Phakopsora pachyrhizi Sydow \& Sydow e aspectos epidemiológicos e ultra-estruturais da sua interação com a soja (Glycine max (L.). Merril). 2005. 92p. Dissertação (Mestrado) - Universidade Federal de Lavras, Lavras, MG. 